\title{
Preliminary report of a clinical trial supporting the sequential use of an attenuated E39 peptide (E39') to optimize the immunologic response to the FBP (E39+GM-CSF) vaccine
}

\author{
Doreen Jackson ${ }^{1 *}$, Na Qiao 2 , Julia M Greene ${ }^{3}$, Diane Hale ${ }^{3}$, John Berry ${ }^{3}$, Alfred Trappey $^{3}$, Timothy Vreeland ${ }^{3}$, \\ Guy Clifton ${ }^{4}$, Nuhad Ibrahim ${ }^{4}$, Annie Toms ${ }^{4}$, George E Peoples ${ }^{5}$, Elizabeth A Mittendorf ${ }^{2}$
}

From 30th Annual Meeting and Associated Programs of the Society for Immunotherapy of Cancer (SITC 2015) National Harbor, MD, USA. 4-8 November 2015

\section{Background}

Folate Binding Protein (FBP) is overexpressed in breast, endometrial, and ovarian cancers. E39 (FBP191-199, EIWTHSYKV) is an HLA-A2 restricted FBP peptide vaccine already shown to generate significant in vivo immunologic response (IR) in a Phase I/IIa trial in endometrial and ovarian cancer. We are investigating a novel vaccination series using E39 and E39' (EIWTFSTKV), an attenuated version of E39, in a Phase Ib, randomized, single-center trial (NCT020196524) evaluating IR and monitoring longterm immunity. We present the initial IR analysis to the primary vaccination series (PVS).

\section{Methods}

HLA-A2+ breast or ovarian cancer patients were enrolled after completion of standard of care therapy and randomized into three arms: EE-6 inoculations of E39; EE'-3 inoculations of E39 then 3 of E39'; or E'E-3 inoculations of E39' then 3 of E39. PVS includes 6 inoculations total, one every 3-4 weeks containing $250 \mathrm{mcg}$ GM-CSF + $500 \mathrm{mcg}$ peptide in the first 5 patients per arm and $1000 \mathrm{mcg}$ of peptide in second 5 patients. To assess the in vivo IR, local reaction(LR) was measured 48 hours after each inoculation (R1-6), and delayed type hypersensitivity (DTH) was measured pre-vaccine(R0), 1 and 6-months after the PVS (RC1, RC6). Ex vivo IR was measured via dextramer assay for E39-specific CD8+ T-cells at R0, RC1, and RC6. Statistical analyses included descriptive

${ }^{1}$ San Antonio Military Medical Center, Converse, TX, USA Full list of author information is available at the end of the article statistics, t-test, Chi-squared, Fisher's exact test and ANOVA as appropriate.

\section{Results}

Thirty-two patients were enrolled (EE $n=10, E E^{\prime} n=11$, $E^{\prime} E \mathrm{n}=11$ ), with no clinicopathologic differences between groups, or significant toxicities appreciated. In vivo LR showed a significant difference within EE and EE' arms. LR peaked in EE at R4, while EE' continued to increase in size throughout the PVS(EE $p=0.04, E E^{\prime} p=0.02$, E'E $\mathrm{p}=0.74)$. An increase in in vivo DTH was observed within arm EE' from R0-RC1-RC6 (EE $\mathrm{p}=0.72$, EE' $\mathrm{p}<$ 0.05 , E'E $\mathrm{p}=0.41$ ). Ex vivo analysis of IR revealed no significant difference between groups $(\mathrm{p}=0.39)$, nor within groups ( $\mathrm{EE} \mathrm{p}=0.82, \mathrm{EE}^{\prime} \mathrm{p}=0.58, \mathrm{E}^{\prime} \mathrm{E} \mathrm{p}=0.49$ ).

\section{Conclusion}

In this Phase Ib trial comparing three vaccination strategies in ovarian and breast cancer patients, preliminary analysis revealed E39, given sequentially with or without E39', is immunogenic. The in vivo response is enhanced with the use of the attenuated E39' after E39. This was observed in the EE' arm, this vaccination sequence producing the most prominent LR and DTH responses. Continued analysis of immunologic responses as more data is obtained will further elucidate the optimal vaccination series for the prevention of recurrence in breast and ovarian cancer.

\section{Trial registration}

ClinicalTrials.gov identifier NCT020196524. 


\section{Authors' details}

${ }^{1}$ San Antonio Military Medical Center, Converse, TX, USA. ${ }^{2}$ The University of Texas MD Anderson Cancer Center, Houston, TX, USA. ${ }^{3}$ San Antonio Military Medical Center, San Antonio, TX, USA. ${ }^{4}$ MD Anderson Cancer Center,

Houston, TX, USA. ${ }^{5}$ Cancer Vaccine Development Program, San Antonio, TX USA.

Published: 4 November 2015

doi:10.1186/2051-1426-3-S2-P156

Cite this article as: Jackson et al: Preliminary report of a clinical trial supporting the sequential use of an attenuated E39 peptide (E39') to optimize the immunologic response to the FBP (E39+GM-CSF) vaccine. Journal for ImmunoTherapy of Cancer 2015 3(Suppl 2):P156.

Submit your next manuscript to BioMed Central and take full advantage of:

- Convenient online submission

- Thorough peer review

- No space constraints or color figure charges

- Immediate publication on acceptance

- Inclusion in PubMed, CAS, Scopus and Google Scholar

- Research which is freely available for redistribution

Submit your manuscript at www.biomedcentral.com/submit 